\title{
ON A NEW METHOD OF WRITING CRYSTALLOGRAPHIC FORMUL丑.
}

SrR,-All mineralogists, or at any rate all whose hard lot it is to be commencing the study of mineralogy, must cordially agree with Mr. Rutley that it "would doubtless be productive of much satisfaction if a universal system of crystallographic notation could be adopted." There is no doubt that the many difficulties with which mineralogy unnecessarily bristles are largely due to confusion, resulting from the conflicts of rival methods of classification and nomenclature, and of different systems of crystallography. I have carefully compared the new method unfolded by Mr. Rutley in the Geor. Mag. for July (p. 299) with the principal systems now in vogue, and as it does not seem to have merits so pre-eminent as to insure its sweeping all others from the field, it is doubtful whether its partial acceptance will not place one more obstacle in the student's path.

The system of crystallography originated, I believe, by Dr. Whewell, perfected by Professor Miller, and accepted by Professor Haidinger, contrasts more favourably even than that of Naumann, with Mr. Rutley's new method; and I am surprised that no reference is made to it by the author. I question much whether the concise hieroglyphs of Mr. Rutley will be found so easy to imitate as the more accustomed symbols of Naumann, or the plain indices of Miller;-both these have the immense advantage of being already familiar to mathematicians, and without some mathematical skill, extended acquaintance with crystallography is well nigh hopeless. The introduction of this new method, too, involves the replacement of certain known symbols by others hitherto used with different meanings, as well as the alteration in value of some that are retained. Thus the substitution of a dot for the usually accepted sign of infinity is a loss rather than a gain: a dot, in manuscript, generally causes perplexity, which the close neighbourhood of small vertical and horizontal strokes will, in the new method, much intensify.

In the calculations that occur in the more advanced parts of crystallography, the inferiority of the "new method" to that of Professor Miller becomes more and more apparent. We do not suppose that Mr. Rutley intends to limit the application of his system to the mere beginning of crystallographic science;- to assume this would be at once to pronounce the system unprofitable. Professor Miller's indices are perfectly adapted for employment in mathematical investigations, and practical numerical results are at once obtained by simple substitution at the end of such process. But if Mr. Rutley's "prolonged vertical cross" and "curved line" take the place of the "conventional distances $m$ and $n$," numbers must be substituted for them throughout the calculations, the labour of which is thereby greatly increased; for these difficult signs would undergo a process of natural deterioration in the mazes of hastily, perhaps carelessly, written mathematical analysis, and would, certainly, be illegible at the end of it.

Downing College, Cambridge. $\quad$ T. W. Danby, M.A. 